\title{
Identification and differentiation of Candida species from pediatric patients by random amplified polymorphic DNA
}

\author{
Identificação e diferenciação de espécies de Candida \\ de pacientes pediátricos por amplificação aleatória \\ de DNA polimórfico
}

\author{
Bruno Aragão Rocha ${ }^{1}$, Gilda Maria Barbaro Del Negro ${ }^{1}$, Lidia Yamamoto ${ }^{1}$, \\ Mariana Vitule Brito de Souza ${ }^{1}$, Alexander Roberto Precioso ${ }^{1}$ and Thelma Suely Okay ${ }^{1}$
}

\begin{abstract}
Thirty-four Candida isolates were analyzed by random amplified polymorphic DNA using the primer OPG-10: 24 Candida albicans; 4 Candida tropicalis; 2 Candida parapsilosis; 2 Candida dubliniensis; 1 Candida glabrata and 1 Candida krusei. The UPGMA-Pearson correlation coefficient was used to calculate the genetic distance between the different Candida groupings. Samples were classified as identical (correlation of 100\%); highly related samples (90\%); moderately related samples $(80 \%)$ and unrelated samples $(\leq 70 \%)$. The results showed that the RAPD proposed was capable of classifying the isolates coherently (such that same species were in the same dendrogram), except for two isolates of Candida parapsilosis and the positive control (Netherlands, 1973), probably because they are now recognized as three different species. Concerning the only fluconazole-resistant Candida tropicalis isolate with a genotype that was different to the others, the data were insufficient to affirm that the only difference was the sensitivity to fluconazole. We concluded that the Random Amplified Polymorphic DNA proposed might be used to confirm Candida species identified by microbiological methods.
\end{abstract}

Key-words: RAPD. Candidiasis. Candida spp. Polymorphism. Molecular typing.

\section{RESUMO}

Trinta e quatro isolados de Candida foram analisados por amplificação aleatória de DNA polimórfico (primer OPG-10): 24 Candida albicans, 4 Candida tropicalis, 2 Candida parapsilosis, 2 Candida dubliniensis, 1 Candida glabrata e 1 Candida krusei. 0 coeficiente de correlação de Pearson-UPGMA calculou a distância genética entre os diferentes agrupamentos de Candida: amostras idênticas (100\% de correlação), amostras muito relacionadas $(90 \%)$, moderadamente relacionadas $(80 \%)$, e não relacionadas $(\leq 70 \%)$. Os resultados demonstram que a amplificação aleatória de DNA polimórfico proposta é capaz de classificar os isolados de forma coerente, ficando os de mesma espécie em um mesmo dendograma, com exceção dos dois isolados de Candida parapsilosis e o controle positivo (Holanda, 1973), provavelmente por serem atualmente classificadas em três espécies diferentes. Quanto ao único isolado de Candida tropicalis resistente ao fluconazol com genótipo diferente dos outros, os dados não são suficientes para afirmar que a única característica distinta fosse a sensibilidade ao fluconazol. Concluímos que a amplificação aleatória de DNA polimórfico proposta poderia ser usada para a confirmação das espécies de Candida identificadas nos testes microbiológicos.

Palavras-chaves: Amplificação aleatória de DNA polimórfico. Candidíase. Candida spp. Polimorfismo. Tipagem molecular.

Due to the rise in pediatric Candida infections and the associated epidemiological issues (increasing numbers of immunocompromised children, prolonged hospital stays, indiscriminate use of broad-spectrum antibiotics, parenteral nutrition and insertion of central venous and arterial catheters $)^{414}{ }^{18}$, rapid and reliable identification of yeasts at species level is extremely important.
The standard culturing methods and differentiation of Candida species are time-consuming, lack sensitivity and may fail to distinguish Candida non-albicans species ${ }^{1220}$. Blood cultures may be negative in up to $50 \%$ of autopsy-proven cases of systemic candidiasis, or may only become positive at a late stage in the infection. Positive cultures from urine or mucosal surfaces do not necessarily indicate invasive disease, although this may occur

1. Laboratory of Medical Investigation, Department of Pediatrics, Faculdade de Medicina da Universidade de São Paulo, SP.

Address to: Prof Thelma Suely Okay. Laboratory of Medical Investigation (LIM/36), Children's Institute, Hospital das Clínicas da Faculdade de Medicina da Universidade de São Paulo. Av. Dr. Enéas Carvalho de Aguiar 647, Cerqueira César, 05403-900 São Paulo, SP, Brasil.

Tel: 5511 3069-8606; Fax: 5511 3069-8591

e-mail: tsokay@icr.hcnet.usp.br

Recebido para publicação em 24/4/2007

Aceito em 28/1/2008 
before systemic infection. Therefore, blood cultures should be systematically requested in all cases of at-risk patients, regardless of the difficulties in obtaining blood, in order to perform life-sustaining tests and blood cultures on critically ill pediatric patients9.

Recently, molecular typing has been used to identify Candida species $^{51121}$. These tests can be accomplished within one working day, whereas microbiological methods are more timeconsuming ${ }^{10}$. The random amplified polymorphic DNA (RAPD) technique has proven to be useful for typing many microbiological agents, including Candida species ${ }^{12224}$.

The present study proposed the use of a single short primer for confirming the microbiological Candida species identification, by means of RAPD. Since Candida species have innate pathogenicity as well as variation in antifungal susceptibility, identification at species level might be relevant for clinical management ${ }^{9}$.

\section{MATERIAL AND METHODS}

This study was approved by the Ethics Committee of the University of São Paulo School of Medicine, Brazil (CAPPesq protocol number 1213/05).

Candida spp isolates. Forty Candida spp samples from newborns or children were isolated and identified by standard microbiological methods ${ }^{10}$ at the Mycology Laboratory of the Adolfo Lutz Institute, a reference center in the city of São Paulo, Brazil.

Confirmation of microbiological identification of Candida isolates. A previously described nested PCR method was used to confirm microbiological species identification of Candida albicans, Candida tropicalis, Candida parapsilosis, Candida glabrata and Candida krusei isolates ${ }^{13}$. Briefly, in the first round of amplification, gender-specific primers were designed within the internal transcribed spacer (ITS) region and were called ITS1 and ITS4. During the second round of amplification, species-specific primers were designed to amplify only one Candida species: CALB1 and CALB2 for Candida albicans; CTR1 and CTR2 for Candida tropicalis; CPA2 and CPA3 for Candidaparapsilosis; CGL1 and CGL2 for Candida glabrata. Candida krusei-specific amplification was performed with the primers CKR2 and CKR $3^{3}$. The first-round amplification for Candida dubliniensis was performed using the fungus-specific universal primers ITS-3 and ITS-4, designed within the $5.8 \mathrm{~S}$ rDNA region, and in the second round within the $28 \mathrm{~S}$ rDNA region, yielding a 343 bp fragment ${ }^{17}$.

The nested ITS-PCR revealed that 34 of the $40(85 \%)$ isolates were correctly identified at species level, and were thereafter included in the study. The characteristics of the 34 isolates are described in Table 1.

Reference strains (prototype species used as controls). ATCC Candida strains of the following species (albicans, tropicalis, glabrata, krusei and dubliniensis) were used as prototypes (controls) in order to define the DNA banding patterns obtained by RAPD corresponding to each species. The ATCC numbers were: 36082 Candida albicans (sensitive to fluconazole); 204276 Candida albicans (resistant to fluconazole); 204318 Candida tropicalis (sensitive to fluconazole); 200918 Candida glabrata; 200917 Candida krusei; and MYA-577 Candida dubliniensis.
Table 1 - Characteristics of the 34 isolates analyzed by microbiological methods, nested ITS-PCR and random amplified polymorphic DNA.

\begin{tabular}{lccc}
\hline Isolate & Biological sample & Candida species & Fluconazole \\
\hline $1-16$ & blood & albicans & $\mathrm{S}$ \\
$17-20$ & blood & albicans & $\mathrm{R}$ \\
$21-23$ & oropharynx & albicans & $\mathrm{R}$ \\
24 & urine & albicans & $\mathrm{R}$ \\
$25-27$ & blood & tropicalis & $\mathrm{S}$ \\
28 & blood & tropicalis & $\mathrm{R}$ \\
$29-30$ & blood & parapsilosis & $\mathrm{S}$ \\
31 & blood & dubliniensis & $\mathrm{S}$ \\
32 & blood & dubliniensis & $\mathrm{R}$ \\
33 & oropharynx & glabrata & $\mathrm{S}$ \\
34 & blood & krusei & $\mathrm{R}$ \\
\hline $\mathrm{S}:$ fluconazl &
\end{tabular}

$\mathrm{S}$ : fluconazole-sensitive, $\mathrm{R}$ : fluconazole-resistant.

The Candida parapsilosis strain used as a control was kindly sent by the Central Bureau of Fungal Cultures (Centraalbureau voor Schimmelcultures) of the Royal Netherlands Academy of Arts and Sciences, to the Mycology Laboratory of the Tropical Medicine Institute (Instituto de Medicina Tropical) of São Paulo, Brazil, in 1973.

DNA extraction of Candida spp isolates. The DNA extraction of Candida isolates was performed in accordance with a protocol described elsewhere ${ }^{25}$. Briefly, $500 \mu \mathrm{l}$ of the fungal suspension were spun at $15,300 \mathrm{~g}$ for $5 \mathrm{~min}$ in a refrigerated centrifuge (Eppendorf, 5417R) and the pellet was mixed with $600 \mu \mathrm{l}$ of a solution containing $50 \mathrm{mM}$ Tris, $10 \mathrm{mM}$ EDTA, $250 \mathrm{U} / \mathrm{ml}$ lyticase (L2524, Sigma) and 10\% $\beta$-mercaptoethanol. The samples were then kept at $37^{\circ} \mathrm{C}$ for two and a half hours to promote cell wall digestion. Following this, $0.2 \%$ SDS and $200 \mu \mathrm{g} / \mathrm{ml}$ proteinase $\mathrm{K}$ (Sigma) were added to the samples, which were kept at $65^{\circ} \mathrm{C}$ for $45 \mathrm{~min}$ in order to obtain nuclear lysis and protein digestion. The samples were then centrifuged at $15,300 \mathrm{~g}$ for $5 \mathrm{~min}$. The supernatants were mixed with isopropanol (Merck) $(\mathrm{v} / \mathrm{v})$ and these samples were kept overnight at $-20^{\circ} \mathrm{C}$. After centrifugation again at $15,300 \mathrm{~g}$ for $5 \mathrm{~min}$, the pellet containing DNA was rehydrated with $500 \mu 1$ of $70 \%$ ethanol (Merck) and the final DNA pellet was resuspended in 1M Tris-EDTA buffer.

Random amplified polymorphic DNA. The assays were performed in a total volume of 50 $\mathrm{\mu l}$, containing $5 \mathrm{ng}$ of genomic DNA from each Candida isolate or strain (ATCC prototype), $0.4 \mu \mathrm{M}$ of the OP-G10 primer 5'-AGGGCCGTCT-3' (IDT, USA); $600 \mu \mathrm{M}$ of each dNTP (Amersham Biosciences); $3.5 \mathrm{mM}$ of $\mathrm{MgCl}_{2}$; and $5 \mathrm{U}$ of Taq DNA polymerase (Promega). The amplification consisted of 40 cycles: $1 \mathrm{~min}$ at $95^{\circ} \mathrm{C}, 2 \mathrm{~min}$ at $25^{\circ} \mathrm{C}$ and $2 \mathrm{~min}$ at $72^{\circ} \mathrm{C}$, followed by a final extension of $5 \mathrm{~min}$ at $72^{\circ} \mathrm{C}$ (PT-150, Minicycler, MJ Research). Ten microliters of each PCR product were analyzed by horizontal electrophoresis (Horizon 58, Gibco) in 1.5\% ethidium bromidestained agarose gels (Sigma) prepared in 1X TAE buffer.

Statistical analysis. The RAPD results were used to build up a binary matrix by means of the Unweighted Pair-Group Method using Arithmetic Averages (UPGMA; GelWorks-1 AD Bioimaging System, Upland, CA, USA), to generate dendrograms representing clusters of similarities. The degree of similarity was then calculated by applying the Dice coefficient test, which was able to analyze the 
matches and mismatches between pairs of DNA profiles according to the presence or absence of bands. In the second part of the statistical analysis, the similarity correlation coefficient was calculated using the same software coupled to Pearson's correlation coefficient test, and this was used to determine the genetic relatedness of strains or isolates analyzed in pairs (two by two) ${ }^{816}$. In accordance with the proposal by Dassanayake \& Samaranayake ${ }^{7}$, the strains were classified in terms of the similarity correlation coefficient, as follows: 1.0 or $100 \%=$ identical samples; 0.9 or $90 \%=$ highly related samples; 0.8 or $80 \%=$ moderately related samples; and $\leq 0.7$ or $70 \%=$ unrelated samples.

\section{RESULTS}

The RAPD banding patterns using the primer OP-G10 for the different Candida isolates and corresponding prototypes (controls) are shown in Figure 1.

The UPGMA-Dice similarity coefficient test generated dendrograms representing 19 clusters of similarity, with degrees of similarity ranging from 70 to $100 \%$ (data not shown).

The second part of the statistical analysis used the UPGMAPearson correlation coefficient test to determine the genetic distance (or relatedness) between pairs of Candida clusters (dendrograms) (Figure 2):

Using these criteria, Figure 2 yielded the following results.

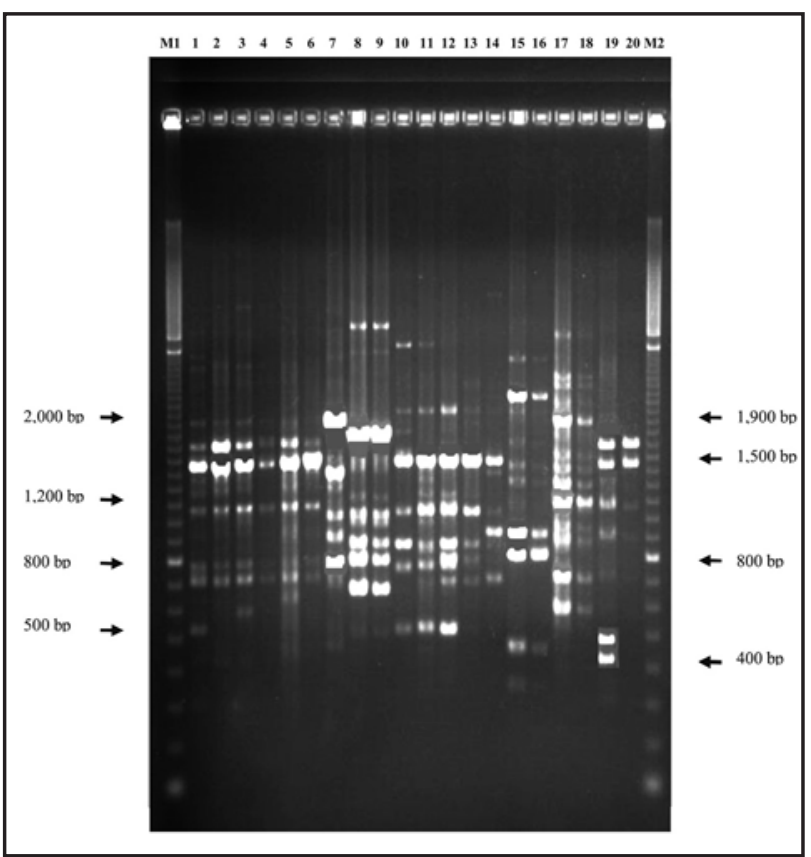

Figure 1 - Random amplified polymorphic DNA banding pattern with the primer OP-G10.

Lanes M1 and M2, molecular weight marker 100 bp (Amersham); lane 1 Candida albicans $S$ control; lanes 2 to 4 Candida albicans $S$; lane 5 Candida albicans $\boldsymbol{R}$ control; lane 6 Candida albicans $\boldsymbol{R}$; lane 7 Candida parapsilosis $S$ control; lanes 8 and 9 Candida parapsilosis $S$; lane 10 Candida tropicalis S control; lanes 11 to 13 Candida tropicalis S; lane 14 Candida tropicalis $R$; lane 15 Candida glabrata $S$ control; lane 16 Candida glabrataS; lane 17 Candida krusei R comtrol; lane 18 Candida krusei $\boldsymbol{R}$; lane 19 Candida dubliniensis $\boldsymbol{S}$ control; lane 20 Candida dubliniensis $\boldsymbol{S}$.

S: fluconazole-sensitive, R: fluconazole-resistant.

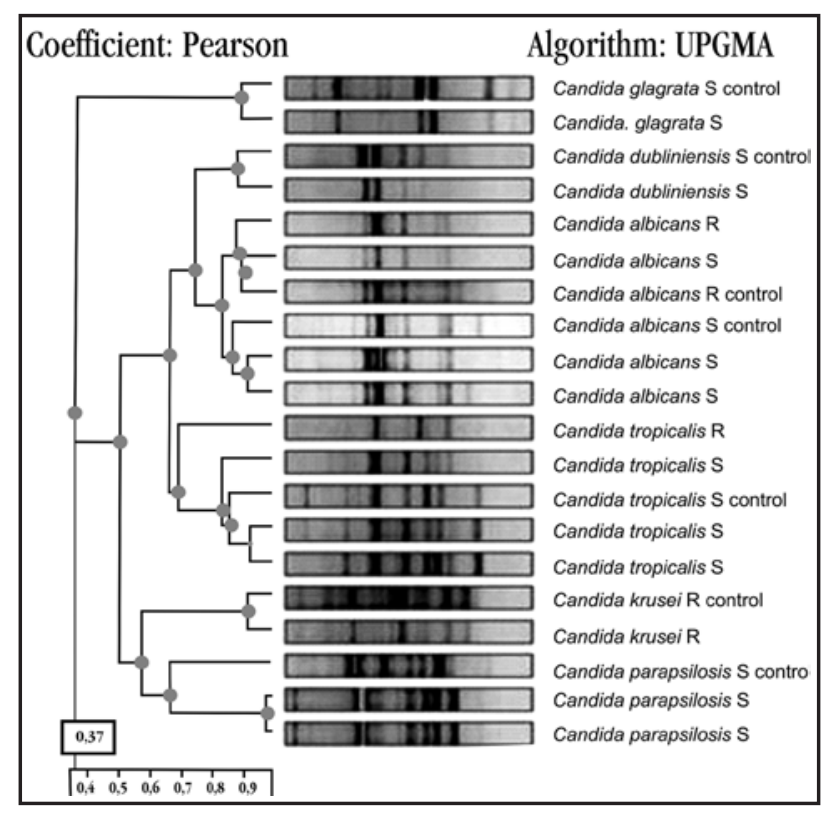

Figure 2 - The dendrograms representing the clusters of similarity were classified according to the degree of genetic relatedness 7 : 1.0 or $100 \%$ for identical samples; 0.9 or $90 \%$ for highly related samples; 0.8 or $80 \%$ for moderately related samples; and $\leq 0.7$ or $70 \%$ for unrelated samples.

- 1.0 or $100 \%$ (identical samples):

Cpar 1 versus Cpar 2.

- 0.9 or $90 \%$ (highly related samples):

Cglab versus CglabC+;

Cdublin versus CdublinC+;

CalbR, Calb3S versus CalbC+R;

CalbC+, Calb1S versus Calb2S;

Ctrp3S, CtrpC+, Ctrp1S versus Ctrp2S;

CkrusC+ versus Ckrus.

- 0.8 or $80 \%$ (moderately related samples): the two Candida dubliniensis studied (sample and control) versus all the Candida albicans studied.

- $\leq 0.7$ or $\leq 70 \%$ (unrelated samples):

- all Candida dubliniensis and Candida albicans versus all Candida tropicalis;

○ the only fluconazole-resistant Candida tropicalis (CtrpR) versus all other Candida tropicalis studied;

- the Candida parapsilosis prototype ( $\mathrm{CparC}+$ ) versus the two Candida parapsilosis studied (Cpar1 and Cpar2);

- the two Candida krusei (control and isolate) versus the three Candida parapsilosis (CparC+, Cpar1 and Cpar2);

- all Candida dubliniensis, Candida albicans and Candida tropicalis versus the group of all Candida krusei and Candida parapsilosis;

o the lowest degree of genetic relatedness (37\%) was found between the two Candida glabrata (CglabC+ and the isolate) versus the dendrogram formed by all other isolates and prototypes included in the present study. 


\section{DISCUSSION}

Forty Candida isolates from pediatric patients were identified by microbiological methods, but only 34 (85\%) had the species confirmed by the Candida nested ITS-PCR ${ }^{313}$. We decided to exclude the six isolates that showed discrepancies between microbiological and nested ITS-PCR typing. It is noteworthy that the nested ITS-PCR and RAPD with the primer OP-G10 yielded identical results for all 40 isolates. Unreliability concerning identification of Candida species by microbiological techniques has already been reported ${ }^{122}$. To circumvent this problem, a complex diagnostic algorithm based on a three-step procedure integrating morphological criteria, biochemical investigation and sequence analysis of the ITS region in order to achieve unequivocal identification of Candida species was proposed in a recent study

The fact that the two Candida parapsilosis included in the study were classified as unrelated to the control (degree of relatedness $\leq 70 \%$ ) indicates that RAPD with the primer $\mathrm{OPG}$ 10 was able to discriminate between species. The two Candida parapsilosis were recovered from patients recently, while the prototype was sent from the Netherlands a long time ago, in 1973. At that time, the three species Candida parapsilosis, Candida orthopsilosis and Candida metapsilosis were considered to be a single species ${ }^{23}$. Moreover, the RAPD proposed was able to discriminate between one of the Candida tropicalis studied and the other three Candida tropicalis isolates (genetic relatedness $\leq 70 \%$ ). For the moment, it is not possible to determine whether this finding might be attributable to fluconazole sensitivity. Other molecular tests such as DNA sequencing and gene expression assays will have to be performed in order to clarify this finding.

The RAPD used in the present study provided an accurate and rapid technique for identifying and differentiating Candida species. However, it had some disadvantages: the accuracy of DNA patterns relies on strict maintenance of reagent concentration, template DNA extraction protocol, amplification parameters and thermal cycler type ${ }^{15}$. RAPD cannot be used to determine Candida species directly from biological samples without prior culture isolation. Although the DNA fragments generated by RAPD cover the entire fungus genome, they are not associated with any of the four proposed mechanisms that lead, for instance, to triazole compound resistance: failure of drug accumulation, alteration in Erg11p, upregulation of ERG11, and alteration in sterol composition ${ }^{19}$.

Apart from corroborating previous studies that reported failure of microbiological techniques to identify Candida species $^{122}$, the present study has successfully identified Candida isolates. It was able to discriminate between species through the use of a single primer, while other studies have reported success in Candida species typing through the use of a set of primers ${ }^{24}$.

We conclude that RAPD with the primer OP-G10 could be performed after culture isolation, in order to confirm microbiological species identification, thus providing faster and more reliable Candida species typing.

\section{ACKNOWLEDGEMENT}

The authors thank Maria Helena Matté, Associate Professor at the Collaborative Center for Sanitary Surveillance (Centro Colaborador em Vigilância Sanitária, CECOVISA), University of São Paulo School of Public Health, for her assistance in using the GelWorks-1 AD Bioimaging System (CA partnership $\mathrm{n}^{\mathrm{0}}$ 06/99-44-ANVS/MS, procedure $\mathrm{n}^{\mathrm{0}}$ 2001.1.1048.6.9).

\section{REFERENCES}

1. Becker K. Molecular biological differentiation of yeasts. Mycoses 43: 40-47, 2000 .

2. Benjamin DK, Garges H, Steinbach WJ. Candida bloodstream infection in neonates. Seminaires in Perinatology 27: 375-383, 2003.

3. Bougnoux M-E, Dupont C, Mateo J, Saulnier P, Faivre V, Payen D, NicolasChanoine M-H. Serum is more suitable than whole blood for diagnosis of systemic candidiasis by nested PCR. Journal of Clinical Microbiology 37: 925-930, 1999.

4. Chapman RL, Faix RG. Invasive neonatal candidiasis: an overview. Seminaires in Perinatology 27: 352-356, 2003.

5. Chen SCA, Halliday CL, Meyer W. A review of nucleic acid-based diagnostic tests for systemic mycoses with emphasis on polymerase chain reaction-based assays. Medical Mycology 40: 333-357, 2002.

6. Ciardo DE, Schär G, Böttger EC, Altwegg M, Bosshard PP. Internal transcribed spacer sequencing versus biochemical profiling for identification of medically important yeasts. Journal of Clinical Microbiology 44: 77-84, 2006.

7. Dassanayake RS, Samaranayake LP. Amplification-based nucleic acid scanning techniques to assess genetic polymorphism in Candida. Critical Reviews in Microbiology 29: 1-24, 2003.

8. Duarte JM, Santos JB, Melo LC. Comparison of similarity coefficients based on RAPD markers in the common bean. Genetics and Molecular Biology 22: 427432, 1999.

9. Ellepola ANB, Morrison CJ. Laboratory diagnosis of invasive candidiasis. Journal of Microbiology 43: 65-84, 2005.

10. Freydiere A-M, Guinet R, Boiron P. Yeast identification in the clinical microbiology laboratory: phenotypical methods. Medical Mycology 39: 9-33, 2001.

11. Haynes, KA, Westerneng TJ. Rapid identification of Candida albicans, C. glabrata, C. parapsilosis and C. kruse $i$ by species-specific PCR of large subunit ribosomal DNA. Journal of Medical Microbiology 44:390-396, 1996.

12. Liu D, Coloe S, Jones SL, Baird R, Pedersen J. Genetic speciation of Candida isolates by arbitrary primed polymerase chain reaction. FEMS Microbiology Letters 145: 23-26, 1996.

13. Luo G, Mitchell TG. Rapid identification of pathogenic fungi directly from cultures by using multiplex PCR. Journal of Clinical Microbiology 40: 2860-2865, 2002.

14. Lupetti A, Tavanti A, Davini P, Ghelardi E, Corsini V, Merusi I, Boldrini A, Campa M, Senesi S. Horizontal transmission of Candida parapsilosis candidemia in a neonatal intensive care unit. Journal of Clinical Microbiology 40: 2363-2369, 2002.

15. MacPherson JM, Eckstein PE, Scoles GJ, Gajadhar AA. Variability of the random amplified polymorphic DNA assay among thermal cyclers, and effects of primer and DNA concentration. Molecular and Cellular Probes 7: 293-299, 1993.

16. Meyer AS, Garcia AAF, Souza AP, Souza Jr CL. Comparison of similarity coefficients used for cluster analysis with dominant markers in maize (Zea mays L). Genetics and Molecular Biology 27: 83-91, 2004.

17. Park S, Wong M, Marras SAE, Cross EW, Kiehn TE, Chaturvedi V, Tyagi S, Perlin DS. Rapid identification of Candida dubliniensis using a species-specific molecular beacon. Journal of Clinical Microbiology 38: 2829-2836, 2000.

18. Saiman L, Ludington E, Dawson JD, Patterson JE, Rangel-Frausto S, Wiblin RT, Blumberg HM, Pfaller M, Rinaldi M, Edwards JE, Wenzel RP, Jarvis W. National 
Epidemiology of Mycoses Study Group. Risk factors for Candida species colonization of neonatal intensive care unit patients. Pediatric Infectious Diseases Journal 20: 1119-1124, 2001.

19. Sanglard D, Odds FC. Resistance of Candida species to antifungal agents: molecular mechanisms and clinical consequences. The Lancet 2: 73-85, 2002.

20. Schelonka RL, Moser SA. Time to positive culture results in neonatal Candida septicemia. Journal of Pediatrics 142: 564-565, 2003.

21. Shin J H, Nolte FS, Morrison CJ. Rapid identification of Candida species in blood cultures by a clinically useful PCR method. Journal of Clinical Microbiology 35:1454-1459, 1997.
22. Steffan P, Vazquez JA, Boikov D, Xu C, Sobel JD, Akins RA. Identification of Candida species by randomly amplified polymorphic DNA fingerprinting of colony lysates. Journal of Clinical Microbiology 35: 2031-2039, 1997.

23. Tavanti A, Davidson AD, Gow NAR, maiden MCJ, Odds FC. Candida orthopsilosis and Candida metapsilosis spp. nov. to replace Candida parapsilosis groups II and III. Journal of Clinical Microbiology 43: 284-292, 2005.

24. Valério HM, Weikert-Oliveira RCB, Resende MA. Differentiation of Candida species obtained from nosocomial candidemia using RAPD-PCR technique. Revista da Sociedade Brasileira de Medicina Tropical 39: 174-178, 2006.

25. Van Burik J, Myerson D, Schreckhise RW, Bowden RA. Panfungal PCR assay for detection of fungal infection in human blood specimens. Journal of Clinical Microbiology 36: 1169-1175, 1998. 